\title{
A HISTÓRIA DO INÍCIO DAS POLÍCIAS NO BRASIL
}

\author{
Antonio José Ferreira Gomes ${ }^{1}$
}

RESUMO: Na sociedade, a força policial é perpassada por diversos contextos relativos às concepções que nortearam as relações sociais ao longo da história. Compreender o processo histórico que faz com que hoje a polícia esteja envolvida em uma série de polêmicas em relação ao uso abusivo de sua força, atrelada ao caos na segurança pública do país, a qual não dá conta de atender às demandas da sociedade, é fundamental para que o fazer policial possa ser discutido, e para além, seja repensado de forma a construir novos pressupostos que possam contribuir na resolução dos conflitos que norteiam as relações sociais. A metodologia utilizada para compor o presente estudo foi de cunho bibliográfico, exploratória e abordagem qualitativa, com busca através de meio físico e digital, através da base da dados Scielo e Google Acadêmico. Implicar-se na história do início da polícia no Brasil permite a elucidação dos paradigmas de violência principalmente em relação às camadas marginalizadas da população na contemporaneidade. A história brasileira de colonização e escravidão infringe reflexos expressivos nas relações sociais que são estabelecidas na atualidade, e neste âmbito, a polícia sempre possui um papel repreensivo, com finalidade de controle social por parte do Estado e das classes dominantes.

Palavras-Chaves: Polícia. Historiografia policial. Segurança Pública. Violência policial.

ABSTRACT: In society, the police force is permeated by different contexts related to the conceptions that guided social relations throughout history. Understanding the historical process that makes the police today involved in a series of controversies regarding the abusive use of their force, linked to the chaos in the country's public security, which is unable to meet the demands of society, is essential so that police work can be discussed, and beyond that, it can be rethought in order to build new assumptions that can contribute to the resolution of conflicts that guide social relations. The methodology used to compose this study was bibliographical, exploratory and qualitative approach, with search through physical and digital means, through the database Scielo and Google Academic. Getting involved in the history of the beginning of the police in Brazil allows for the elucidation of the paradigms of violence, especially in relation to the marginalized layers of the population in contemporary times. The Brazilian history of colonization and slavery infringes on expressive effects on social relations that are

\footnotetext{
${ }^{I}$ Pós-Graduado em Inteligência Policial e Penitenciária pela Faculdade Verbo Educacional (2020); PósGraduado em Políticas e Gestão em Segurança Pública pela Universidade Estácio de Sá (2019); PósGraduado em Docência do Ensino Superior pela Faculdade Metropolitana São Carlos (2020); Possuo o Curso Superior em Tecnologia em Segurança Pública pela Universidade Estácio de Sá (2017). Atualmente é Policial Militar na Polícia Militar do Estado do Rio de Janeiro. E Instrutor no Centro de Formação e Aperfeiçoamento de Praças-CFAP/PMERJ.E-mail: antoniojfgomes@ymail.com.
} 
currently established, and in this context, the police always have a reprehensible role, with the purpose of social control by the State and the ruling classes.

Keywords: Police. Police historiography. Public security. Police violence.

\section{INTRODUÇÃO}

$\mathrm{Na}$ sociedade, a força policial é perpassada por diversos contextos relativos às concepções que nortearam as relações sociais ao longo da história. No Brasil, a realidade vivenciada na atualidade, a qual representa uma série de conflitos relacionados à polícia, à violência e aos abusos cometidos por quem em teoria seria responsável por "manter a ordem" entre os mais distintos grupos, denotam de um processo histórico que culmina no que sé é praticado por estas forças nos dias de hoje.

A historiografia da polícia pode ser considerada uma temática recente, decorrente das últimas décadas, a qual veio de encontro com o processo de democratização do país, visto que, principalmente a partir da nova Constituição, emergiram diversos debates relacionados a construção da cidadania e a prevalência de direitos sociais, os quais alcançaram também o âmbito da segurança pública.

Este contexto impulsionou um crescimento em relação as pesquisas sobre como a força policial se desenvolveu ao longo dos anos, em uma tentativa principalmente de transformação dos pressupostos advindos do período da colonização e que hoje, trazem uma série de problemas em relação à forma como se implicam na resolução das desordens do país.

Nesse sentido, compreender o processo histórico que faz com que hoje a polícia esteja envolvida em uma série de polêmicas em relação ao uso abusivo de sua força, atrelada ao caos na segurança pública do país, a qual não dá conta de atender às demandas da sociedade, é fundamental para que o fazer policial possa ser discutido, e para além, seja repensado de forma a construir novos pressupostos que possam contribuir na resolução dos conflitos que norteiam as relações sociais.

Sendo assim, a questão norteadora do presente estudo é: Como a história do início das polícias no Brasil influencia a forma como se organizam as forças policiais na atualidade, no sentido de favorecer uma atuação pautada da violência e na repreensão abusiva, principalmente levando em consideração as ações contra grupos marginalizados da sociedade? 


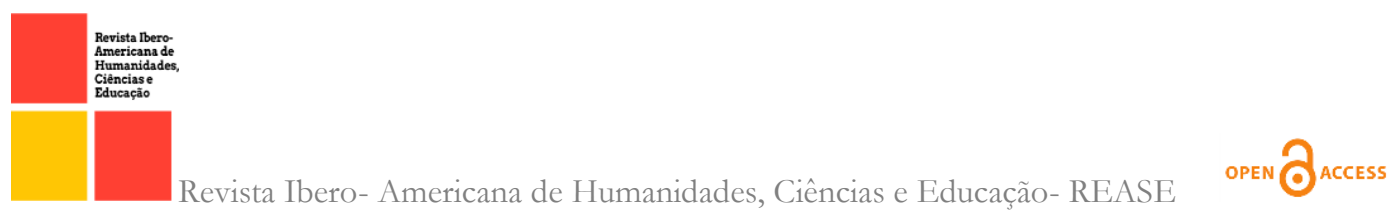

A hipótese é de que a constituição da polícia, em um período pós-colonização traz reflexos que se infundem de maneira estrutural nas práticas policiais na contemporaneidade. Tal exercício se configura principalmente por um foco exacerbado na repreensão de comportamentos considerados desordeiros causando diversas situações de violência, principalmente em relação à grupos marginalizados pela sociedade, causando medo e repulsa a estes profissionais por grande parte da população. Ainda, se atenta para o fato da relação entre a polícia e o Estado no sentido de uma esfera de poder e dominação frente a massa coletiva.

Levando em consideração tais pressupostos, os objetivos que norteiam o presente estudo são:

\section{OBJETIVO GERAL}

- Promover a discussão sobre a história da polícia no Brasil.

\section{OBJETIVOS ESPECÍFICOS}

- Trazer à luz a discussão de como as práticas policiais concebidas no período inicial da polícia do Brasil trazem problemáticas preocupantes levando em consideração o cenário atual da segurança pública do país.

- Promover a discussão sobre a relação entre a polícia, política e o Estado como forma de compreensão sobre as influências que estes exercem na forma como as forças policiais são empregadas no controle dos conflitos sociais.

- Promover reflexões sobre a necessidade de mudanças dos paradigmas em relação às metodologias empregadas pela polícia para manter a ordem pública e a paz na sociedade.

A partir dos objetivos apresentados, a metodologia utilizada para a elucidação desta pesquisa é cunho bibliográfico exploratória e de abordagem qualitativa. Para tanto, utiliza-se nesta pesquisa então, publicações dispostas em livros, revistas, periódicos e outros materiais disponíveis em rede física e digital, as quais foram levantadas a partir da busca nas plataformas digitais Google Acadêmico e Scielo.

A pesquisa bibliográfica está centrada na busca por materiais já publicados, que representam relevância para sociedade e para a ciência. Segundo Alyrio (2009) a pesquisa 
bibliográfica é importante por compilar os principais pontos de determinado tema, fornecendo subsídios teóricos para fundamentação e discussão de determinados assuntos. Esse tipo de pesquisa utiliza-se de publicações já reconhecidas e de importância para o assunto debatido, sejam presentes em livros, revistas, periódicos, entre outros. (ALYRIO, 2009)

Quanto à pesquisa exploratória, sua realização está centrada em apresentar uma problemática, e, a partir das discussões levantadas sobre sua temática, atuar criticamente sobre o problema, levantando hipóteses sobre suas prerrogativas (GERHARDT e SILVEIRA, 2009).

No que se refere a pesquisa qualitativa, Neves (1996, p. 2) afirma que as pesquisas qualitativas "buscam visualizar o contexto e, se possível, ter uma integração empática com o processo objeto de estudo que implique melhor compreensão do fenômeno", ou seja, vem de encontro com o proposto no sentido de proporcionar o entendimento do tema de forma não estática, e permitindo um aprofundamento no âmbito qualitativo do cerne do problema apresentado, de forma compreensiva e dinâmica. (NEVES, 1996, p.2).

Então, de acordo com as descrições expostas, a escolha de tais eixo metodológico corroboram de maneira efetiva para o desenrolar dos objetivos. Imbricar-se sobre questões filosóficas e crítico-reflexivas que denotam as relações estabelecidas entre a sociedade e a forma como está se organiza em determinado espaço histórico é de extrema relevância visto que os sujeitos só evoluem enquanto ser e enquanto organização social a partir do momento em que adquire consciência sobre os pressupostos que permeiam seus modos de agir.

Sendo assim, a segunda sessão do presente artigo tem como intuito discutir os contextos que levaram a necessidade de uma historiografia policial, a qual tem se intensificado nos últimos anos. $\mathrm{Na}$ terceira sessão, apresentam-se processos históricos que culminaram no início da polícia no Brasil, trazendo as influências que contribuíram para a construção do segmento no país.

A quarta sessão tem como objetivo a elucidação dos paradigmas que norteiam o assunto no período pós democratização até a contemporaneidade, trazendo à luz a partir do que dizem estudiosos da temática, a discussão sobre a necessidade de mudanças estruturais nas práticas policiais, de acordo com as demandas trazidas pelas novas formas 
de relações da sociedade. Por fim, conclui-se a pesquisa com considerações importantes levantadas ao longo do escopo do trabalho.

\section{I. À LUZ DA NECESSIDADE DE UMA HISTORIOGRAFIA POLICIAL}

Os estudos em relação a história da polícia são recentes, não só no âmbito brasileiro como também ao redor do mundo. Segundo Mauch (2007), a historiografia policial pode situar-se no campo da história do crime, o qual intensificou-se a partir dos anos 1960, principalmente na Europa e nos Estados Unidos, estimulados por outros campos da historiografia.

Para a autora, este movimento se deu por influência de pensadores marxistas como Michel Foucault e Norbert Elias, os quais propunham reflexões teóricos metodológicas com um enfoque social, que propulsionaram investigações a partir de arquivos judiciais e policiais, como forma de encontrar respostas sobre os questionamentos em relação a temática policial (MAUCH, 2007).

De acordo com Mauch (2007), levando em consideração o cenário norteamericano, as pesquisas que buscavam se debruçar mais especificamente sobre a história da polícia tiveram seu início a partir dos anos de I960, com os estímulos de novas produções sociológicas que se entremeavam nas discussões referentes à relação entre as instituições policiais e a população dos Estado Unidos, principalmente do sentido de promover questionamentos sobre violência policial e combate ao crime, visto que, o que acontece é que para além das leis que visam a manutenção da paz, as ações cotidianas são muito mais respaldadas em uma cultura policial já estruturada.

Sobre este fato, Mauch (2007, p. 108) aponta que:

[...] em muitos eventos, a decisão tomada por um policial sobre o que deve ser feito não está prevista na lei nem nos regulamentos. Nesse sentido, sua prática cotidiana seria balizada tanto pela lei e pelos regulamentos da instituição, quanto pelas avaliações que fazem tais profissionais dos acontecimentos e dos indivíduos neles envolvidos, em meio às quais colocam em prática seus próprios valores, já que possuem grande poder de arbítrio na aplicação (ou não) da lei.

Nesse sentido, compreende-se que as concepções em relação a pratica policial são fruto de construções históricas derivadas de diversos fatores tais como as leis, a influência do estado e o contexto social, e sendo assim, ela não somente faz manter a ordem como a reproduz e influencia (MAUCH, 2007). 
Bretas e Rosemberg (2013) aponta ainda que antes deste período, a historiografia existente sobre a polícia era realizada quase que exclusivamente a partir de relatos de antigos policiais, observando-se raro nas ciências sociais. Segundo o autor, o interesse acadêmico pela questão se deu eu uma realidade de ascensão de diversos movimentos sociais e estudantis da década de 196o, os quais ocasionaram uma visibilidade maior em relação a atuação policial, fazendo com esta fosse fico de interesse acadêmico.

Na América Latina, os estudos voltados a tal temática são ainda mais recentes, entrando em um panorama representativo a partir das décadas de 1980 e 1990 (MAUCH, 2007). Segundo Azevedo e Nascimento (2017), o processo de redemocratização dos países latino-americanos a partir da década de 1980 trouxe diversos desafios em virtude da necessidade emergente de mudanças nas relações entre polícia, política e Estado, visto que estas estruturavam-se de maneira contraditória à realidade vigente, revelando uma história institucional que demandaria atenção frente as demandas de uma atuação que levem consideração os novos paradigmas de cidadania.

Segundo Bretas e Rosemberg (2013), o contexto das ditaduras militares dificultava o estudo da história da polícia, visto que, havia um repúdio na aproximação destes dois elementos por parte de ambos. $\mathrm{O}$ autor aponta que mesmo em países que era considerados democráticos, a polícia via na aproximação acadêmica uma ameaça a um esquema altamente confidencial. Nesse sentido, as informações deveriam ser resguardadas como a própria forma de se estabelecer um poder invisível sobre as massas populares.

Nesse sentido, sobre a o recente processo de historiografia policial no Brasil, Bretas e Rosemberg (2013, p. 164) afirma que:

\footnotetext{
Até os dias de hoje, o acesso a acervos em mãos das polícias se faz de forma irregular, possível em alguns momentos e para alguns, impossível noutros momentos ou para outros. Não existe uma política sistemática em arquivos policiais e as dificuldades costumam ser enormes, mesmo quando é possível o acesso, pela precariedade dos arquivos e de seus recursos. Vale notar que os arquivos onde talvez o acesso seja mais fácil e os recursos de pesquisa mais presentes são exatamente os arquivos de polícia política, que passaram a outras instituições com a democratização dos anos 1980 e que vêm atraindo um enorme interesse.
}

Tais questões podem ser observadas, em um contexto atua, a partir das incertezas frequentes quanto a atuação dos policiais, que apesar do período de construção 
democrática, ainda trazem reflexos dos períodos anteriores à ditadura militar. Sendo assim, a luz de tais questões, diversos historiadores têm se debruçado sobre a temática no sentido de possibilitar, partir da compreensão de um processo histórico, a transformação dos paradigmas que cercam a atuação policial na contemporaneidade ( $M A U C H, 2007)$.

\section{A HISTÓRIA DA POLÍ́CIA NO BRASIL}

Implicar-se na história da polícia traz de antemão a necessidade de compreensão da etimologia da palavra, que assim como política, deriva da expressão grega Politea, a qual representa um conjunto de normas e atividades que se relacionam à constituição $e$ também à gestão das cidades. Originalmente, tal expressão se relacionava à "arte de bem governar" e com o passar do tempo, atribui-se a duas sentidos diferentes, porém próximos, o primeiro diz respeito a um conjunto de leis que regem referente à o eixo administrativo de uma cidade, e nesse âmbito inclui-se a moralidade e a ordem pública, e o segundo, o qual condiz aos próprios responsáveis por garantir que tal sistema seja respeitado, ou seja, os policiais (MOTTA, 2006).

Quanto a sua atribuição, conforme Bayley (2006 apud VALENTE, 2012, p. 206) a

polícia pode ser definida como "pessoas autorizadas por um grupo para regular as relações interpessoais dentro deste grupo através da aplicação de força física”. Nesse sentido, o autor propõe uma definição do sujeito "polícia” a partir de três elementos principais: “o uso de força física, a atuação interna e a autorização coletiva". A partir de então, pode-se que levando em consideração este pressuposto, sempre quando há em alguma localidade o uso da força para contenção de problemáticas comunitárias, na qual de certa forma há uma aprovação do grupo, e sendo assim, é praticamente impossível imaginar alguma sociedade isenta do policiamento (VALENTE, 2012, p. 206).

Segundo Valente (2012), a evolução da polícia é resultado de um processo histórico no qual a ordem pública é entendida a partir de um enfoque coletivo, como responsabilidade do Estado. Antes, a manutenção da ordem nas comunidades era realizada a partir da atuação de grupos particulares os quais eram responsáveis por asseguram a convivência de acordos com as leis locais e cumprir a justiça criminal em caso de desordem. 
Com a transposição da responsabilidade de ordem para o domínio público, na modernidade, a segurança se torna um bem coletivo o qual deve ser garantido pelo Estado, fazendo com que este, gradativamente, assuma um monopólio em relação ao controle social e consolide as instituições policiais profissionais. Este movimento faz com que haja a mudança de paradigma em relação à característica de utilização de força física como forma de manutenção da ordem (VALENTE, 2012).

Neste âmbito, para Valente (2012, p. 206):

Com a expansão do poder do Estado, a violência física exercida por particulares se torna ilegítima e o monopólio da força física passa a ser reservado àqueles legitimados pela autoridade central. Passa a ser necessária a consolidação de instituições voltadas à preservação da ordem interna. As forças de segurança pública, nesse propósito, vão se tornando especializadas. É então que a polícia se distingue do Exército e a este passa a ser atribuída a prerrogativa de uso da força física exclusivamente para a defesa externa.

No Brasil, o início da polícia se deu com a chegada da família real portuguesa em I808. O processo de implementação das atividades policiais se deu a partir da adaptação da realidade portuguesa, ou seja, os paradigmas que norteavam as práticas policiais são resultado de uma incorporação do que era exercido em Portugal como metodologia para a manutenção da ordem pública (BRETAS, 1998).

Sobre este fato Cotta (s.d) ressalta que é fundamental a compreensão sobre a transposição do modelo policial adotado em Lisboa para o Brasil, mais especificamente para o Rio de Janeiro. A estrutura policial portuguesa se respaldava fortemente nos pressupostos do modelo francês, o qual era representado pela Lieutenant General de Police e da Gendarmerie.

A Gendarmerie dizia respeito a uma força pública, a qual decorria da época da Revolução Francesa e defendia que o cidadão tinha direito a uma força pública, direito de todos e não de uma unidade particular. Nesse sentido, a força pública estaria voltada a uma garantia de proteção à população, percepção que se diferencia da portuguesa que diz respeito à ordem na cidade, na qual se tem então a criação de uma concepção relacionada à repreensão. Nesse sentido, os conflitos no meio público eram tratados como uma doença que deveria ser tratada, fato que foi transposto para a polícia brasileira (COTTA, s.d).

Então, no ano de 19o8, é criada no Rio de Janeiro uma Intendência Geral de Polícia, a qual funcionava como órgão administrativo que possuía poderes judiciais além de possui encargos em relação à administração da cidade. Posteriormente, em I8o9, como 
a Intendência não possuía uma grande disponibilidade de pessoas que pudessem atender aos inúmeros procedimentos que lhe eram cabíveis, é criada a Divisão Militar da Guarda Real de Polícia, divisão que possui uma estruturação que se assemelhava ao exército, porém, possuía funções relativas as ordens do intendente na manutenção do sossego público (BRETAS, 1998; AZEVEDO, 2017).

A partir deste cenário então é que a polícia brasileira, assim como a portuguesa, começa a assumir uma característica de divisão entre a polícia responsável pelos processos administrativos, a qual é representada hoje pela polícia civil, e a polícia responsável pelo policiamento das cidades, no sentido de garantir a ordem, ou seja, a polícia denominada atualmente como militar (COTTA, s. d.).

Em relação a este fato, Valente (2012, p. 207) apresenta a seguinte constatação:

A estrutura da segurança pública no Brasil sofreu inúmeras transformações ao longo de sua história, ao sabor dos interesses políticos e da tendência mais ou menos autoritária de cada época. $\mathrm{O}$ modelo dicotômico de polícia existente hoje se aproxima mais do francês, considerando a coexistência de uma polícia civil e uma polícia militar. O modelo francês teria influenciado o de Portugal e daí para o Brasil.

Para Cotta (s.d), neste momento a polícia militar se torna um instrumento de do Estado para controle da população, fato que ocorria através da força. A partir de então, a polícia incorpora os preceitos advindos do exército para o controle social, fato que ocorre então como forma de poderio do estado e ainda, das oligarquias, o qual detinham os poderes políticos, e de antemão, necessitavam de certa "ordem" nas cidades.

Neste âmbito, para Wermuth (2018), a Criação da Guarda Real da Polícia da Corte a qual configurava-se como uma braço do exército, com o intuito de manter o sossego da cidade do Rio de Janeiro a partir das ordens do Intendente de Polícia, corresponde à origem das práticas policiais de repressão, principalmente levando em consideração as camadas desfavorecidas pela sociedade, visto que, desde à época, era necessário manter o controle da população em um período pós escravatura, em detrimento da civilidade pregada pela classe dominante.

Sobre este fato, Bretas (1998, p. 223) já afirmava que a polícia se constituiu nos moldes portugueses de soberania patrimonial, no qual os representantes de maior poder aquisitivo obtinham o privilégio de comando no corpo militar, visto que, estes eram os senhores que comandavam o meio político, e assim, a partir da repressão policial, 
construíram meios de manter seus benefícios, inclusive com doações de "proprietários abastados" para a Guarda Real.

Para Azevedo e Nascimento (2016), a polícia no período colonial tinha então o papel de exercer o controle do Estado sobre as massas populares e os escravos, e sobre esta égide, agia de forma arbitraria com o intuito de impor os costumes e cultura de uma sociedade patriarcal e aristocrática. Nesse sentido, a polícia se instituais e permanece em uma lógica militar e repreensiva de combate ao crime.

Segundo Marino (2017), nesse sentido, o principal palco para a formação dos conceitos militares de violência e perseguição, principalmente em relação a população negra foi o Rio de Janeiro. A época, a cidade era a capital do país e sede do governo, então, emergia o medo de um predomínio da população negra a qual poderia acarretar em uma sério de rebeliões que poderiam prejudicar os interesses da elite. Assim, criou-se uma massa repressiva de força e violência contra essa população no sentido de conter quaisquer formas de oposição ao sistema difundido pela classe dominante.

Sobre este fato, Marino (2017, p. 6) coloca:

O medo de viver em uma cidade predominantemente negra, determinava uma, necessária, eficiência dos mecanismos de sujeição e coerção. O forte adensamento populacional tornava o controle da mão-de-obra um trabalho duro, cansativo e estratégico. A mistura de negros libertos e escravizados ensejava um olhar que desconfiava de todos. Todos os negros, libertos ou escravizados, eram suspeitos e objetos da truculência dos aparatos policiais.

Nesse sentido, Wermuth (2018) aponta que a polícia no Brasil e principalmente no Rio de Janeiro nasce da contradição entre os ideais Europeus de liberdade e defesa dos direitos humanos com a lógica de uma sociedade escravocrata que culminou em práticas de controle e repressão da população marginalizada, a qual representava o medo da elite em relação a ameaças contra a ordem e a disciplina que lhe julgassem favoráveis.

Após a implementação do regime republicano, ainda foram poucas as mudanças observadas em relação aos paradigmas fundados no início da implementação da polícia no Brasil. A segregação neste âmbito ainda continuou vigente agora a partir de um viés de higienista das cidades, o qual estava totalmente atrelado à erradicação da pobreza, a qual deveria se desvinculada para às áreas periféricas a fim de "limpar" a área central da cidade (MARINO, 2017, WERMUTH, 2018).

Assim, o fazer policial vai se estabelecendo com um foco político de controle das camadas populares no sentido de exercer uma dominação a fim de garantir os interesses 
das elites dominantes. Nesse sentido, a força policial do Rio de Janeiro sempre serviu de base para as demais instituições brasileiras, perpetuando seus mecanismos de repressão e violência ao longo dos séculos até a atualidade (MARINO, 2017).

\section{A POLÍCIA PÓS REDEMOCRATIZAÇÃO}

Após o período da Ditadura Militar, tinha-se o vislumbre da diminuição da violência da polícia perpetuada durante muitos séculos (MARINO, 2017). Porém, conforme afirmam Azevedo e Nascimento (2016), o Brasil sempre possuiu dificuldade em romper com o modelo policial pautado no militarismo repressivo em detrimento de uma assistência em relação a prevenção e esclarecimentos de crimes de forma cidadã, fato que ficou evidenciado com a transição do regime ditatorial para o democrático.

A polícia brasileira nesse sentido está marcada como uma instituição violenta, contrária aos ideais de direitos humanos, e que tem seus objetivos exclusivamente relacionados a dominação do estado às massas populares (AZEVEDO e NASCIMENTO, 2016). Para Campos e Silva (2018) o processo de criminalização está diretamente relacionado à necessidade de controle social, inclusive no que se diz respeito ao aparato legislativo sobre o que é considerado crime, até a contemporaneidade, não inferindo rupturas com os modelos anteriores a ditadura.

Nesse sentido, Campos e Silva (2018) apontam a seletividade do que é considerado ilegal aos atos que cercam as camadas marginalizadas da sociedade, fato que foi se construindo ao longo da história da polícia e da sociedade brasileira, sendo que os atos de violência na contemporaneidade são legitimados por este processo sócio-histórico.

Sobre este fato, Santos (2020, p. 54) também considera que a sociedade possui uma formação histórica que "remete à filiação de uma rede de já-dito de que a polícia é anticidadã e que age em desfavor dos pretos e pobres, revelando, por sua vez, o saber de uma Formação Discursiva que descredibiliza a confiabilidade na função democrática e humanitária da polícia”

Sendo assim o autor considera fundamental uma reestruturação nos sistemas de segurança pública em adequação aos pressupostos contemporâneos, no qual, haja visto, o sistema capitalista se atribui das concepções de dominação das camadas menos favorecidas para perpetuar seus ideais econômicos, sempre em favor da classe dominante, 
fato que está intrínseco na sociedade e se esconde as sombras das mais diversas esferas da sociedade.

\section{CONSIDERAÇÕES FINAIS}

Implicar-se na história do início da polícia no Brasil permite a elucidação dos paradigmas de violência principalmente em relação às camadas marginalizadas da população na contemporaneidade. A história brasileira de colonização e escravidão infringe reflexos expressivos nas relações sociais que são estabelecidas na atualidade, e neste âmbito, a polícia sempre possui um papel repreensivo, com finalidade de controle social por parte do Estado e das classes dominantes.

Nessa esfera, os negros e os pobres foram sempre subjugados de antemão aos acontecimentos, pré-dispondo o comportamento de violência policial que se perpetuou ao longo dos séculos e que mesmo após o período de democratização continuou intrínseco na sociedade como comportamento aceitável para manutenção da ordem, prerrogativa ainda do período colonial e que hoje corresponde aos ideais da sociedade capitalista de dominação de classes elitistas.

Sendo assim, estudos que contribuam para a problematização deste contexto são fundamentais para que infundir uma nova percepção na sociedade quanto a necessidade de mudanças estruturais em relação aos pressupostos não só da ação policial, como da marginalização das camadas populares.

\section{REFERÊNCIAS}

ALYRIO, Danilo Rovigati. Métodos e técnicas de pesquisa em administração. Rio de Janeiro: Fundação CECIERJ, 2009.

AZEVEDO, Erika Ferreira de. A polícia e suas polícias: Clientela, hierarquia, soldado e bandido. Psicologia: Ciência e Profissão, v. 37, n. 3, p. 553-564, 2017.

AZEVEDO, Rodrigo Ghiringhelli de. NASCIMENTO, Andrea Ana do. Desafios da reforma das polícias no Brasil: Permanência autoritária e perspectivas de mudança Civitas, v. 16, n. 4, p. 653-672, out.-dez, 2016. 


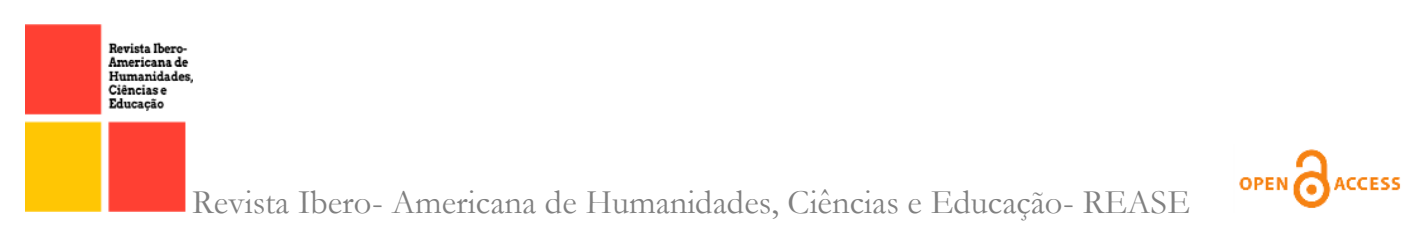

AZEVEDO, Rodrigo Ghiringhelli de. NASCIMENTO, Andrea Ana do. A reforma das polícias na América do Sul: uma abordagem comparativa. Anais do XXXI CONGRESO ALAS URUGUAY, 2017. Disponível em: https://www.easyplanners.net/alas2017/opc/tl/1982_rodrigo_ghiringhelli_de_azevedo.pd f. Acesso em 25 de novembro de 2021.

BRETAS, Marcos Luiz. A polícia carioca no império. Estudos Históricos, n. 22, 1998.

BRETAS, Marcos Luiz. ROSEMBERG, André. A história da polícia no Brasil: balanço e perspectivas. Topoi, v. I4, n. 26, p. 162-173, jan./jul. 2013.

CAMPOS, Gustavo de Aguiar. SILVA, Flávia Maria Soares Pereira da. Polícia e segurança: o Controle Social Brasileiro. Psicologia: Ciência e Profissão, v. 38, n. 2, p. 208222, 2018.

COTTA, Francis Albert. Uma polícia para o império:Historiografia e iconografia sobre a polícia no Rio de Janeiro - primeira metade do século XIX. Disponível em: https://www.fafich.ufmg.br/pae/apoio/umapoliciaparaoimperio.pdf. Acesso em: 26 de novembro de 2021.

GERHARDT, Tatiana Engel. SILVEIRA, Denise Tolfo (Orgs). Métodos de Pesquisa. $\mathrm{I}^{\mathbf{a}}$ Edição. Porto Alegre: Editora UFRGS, 2009.

MARINO, Leonardo Freire. Geografia e poder: o ordenamento territorial da cidade do Rio de Janeiro e a genealogia da violência policial no Brasil. Biblio $3 \mathrm{~W}$, v. 22, n. I.213, 2017 .

MAUCH, Cláudia. Considerações sobre a história da polícia. MÉTIS - história \& cultura, v. 6, n. II, p. 107, 1019, 2007.

MOTTA, Rodrigo Patto Sá. O Ofício das sombras. Arquivo Público mineiro, 2006. Disponível em: http://www.siaapm.cultura.mg.gov.br/acervo/rapm_pdf/O_oficio_das_sombras.PDF. Acesso em: 25 de novembro de 2021. 
NEVES, José Luis. Pesquisa qualitativa: características, usos e possibilidades. Caderno de Pesquisas em Administração. São Paulo, v. I, n. 3, 1996.

SANTOS, Aretuza Pereira dos. O fazer policial: Tensões, conflitos, desordem. Entheoria: Cadernos de Letras e Humanas, v. 7 p. 47-56, Jan./Jun. 2020.

VALENTE, Júlia Leite. "Polícia Militar é um oxímoro": a militarização da segurança pública no Brasil. LEVS, 2012.

WERMUTH, Maiquel Ângelo Dezordi. Biopolítica e polícia soberana: A sociedade escravocrata como chave de compreensão da violência e da seletividade punitiva no Brasil. Rev. direitos fundam. democ., v. 23, n. 3, p. 284-309, set./dez. 2018. 